\title{
Residual Pneumoperitoneum Volume and Postlaparoscopic Cholecystectomy Pain
}

\author{
Amene Sabzi Sarvestani ${ }^{1, *} ;$ Mehdi Zamiri $^{1}$ \\ ${ }^{1}$ Department of Surgery, Imam-Ali Educational Hospital, Zahedan University of Medical Sciences, Zahedan, Iran \\ ${ }^{*}$ Corresponding author: Amene Sabzi Sarvestani, Department of Surgery, Imam-Ali Educational Hospital, Persian Gulf Highway, Zahedan University of Medical Sciences, Zahedan, \\ Iran. Tel: +98-9173156558, Fax: +98-7125223566, E-mail: sabziam@yahoo.com \\ Received: January 4, 2014; Revised: January 25, 2014; Accepted: April 17, 2014
}

\begin{abstract}
Background: Gasretention in the peritoneal cavity plays an important role in inducing postoperative pain after laparoscopy, which is inevitably retained in the peritoneal cavity.

Objectives: The aim of this study was to detect the relation between the volume of residual gas and severity of shoulder and abdominal pain.

Patients and Methods: In this Prospective study 55 women who were referred for laparoscopic cholecystectomy, were evaluated for the effect of residual pneumoperitoneum on postlaparoscopic cholecystectomy pain intensity. The pneumoperitoneum was graded as absent, mild $(1-5 \mathrm{~mm})$, moderate $(6-10 \mathrm{~mm})$ and severe $(>11 \mathrm{~mm})$. Patients were followed for postoperative abdominal and shoulder pain using visual analogue scale(VAS), postoperative analgesic requirements, presence of nausea and vomiting, time of unassisted ambulation, time of oral intake and time of return of bowel function in the recovery room and at 6,12 and 24 hours after operation.

Results: At the end of the study, 17 patients (30.9\%) had no residual pneumoperitoneum after 24 hours; which 23 (41.81\%) had mild residual pneumoperitoneum, eight (14.54\%) had moderate pneumoperitoneum and seven (12.72\%) had severe pneumoperitoneum. Patients with no or mild residual pneumoperitoneum had significantly lower abdominal and shoulder pain scores than whom with moderate to severe pneumoperitoneum $(P=0.00)$ and need less meperidine requirements $(P=0.00)$. Patients did not have any significant difference in time of oral intake, return of bowel function, nausea and vomiting percentages.

Conclusions: We conclude that volume of residual pneumoperitoneum is a contributing factor in the etiology of postoperative pain after laparoscopic cholecystectomy.
\end{abstract}

Keywords: Laparoscopy; Pain; Pneumoperitoneum

\section{Background}

Postoperative pain in laparoscopic cholecystectomy is still a source of marked discomfort and surgical stress although less severe and of shorter duration than that after open cholecystectomy $(1,2)$. It seems that postoperative pain after laparoscopic cholecystectomy are multifactorial - like any other surgery. Thus, the surgeon is in a unique position to influence many of the putative causes by relatively minor changes in the technique (3). It is believed that carbon dioxide gas under the diaphragm is responsible for most of the pain, following laparoscopy and postoperative state. Abdominal and shoulder tip pain is produces by irritation of diaphragm by residual carbon dioxide (4). In 1994 Fredman et al. (5) showed residual pneumoperitoneumis a cause of postoperative pain after laparoscopic cholecystectomy. They did not, however, relate the amount of residual gas to the degree of pain. As far as our knowledge, there is no study about the relationship between residual pneumoperitoneum volume and post laparoscopic cholecystectomy pain and furthermore, Iranian surgeons' attention to aspirate pneumoperitoneum at the end of laparoscopic operations is unknown.

\section{Objectives}

This study evaluates the relationship between the volume of residual pneumoperitoneum and the severity of postoperative pain.

\section{Patients and Methods}

Following local ethics committee approval, In a double blind prospective study, (patients and investigator who collect data were blind) in 55 women with ASA one or two presenting for laparoscopic cholecystectomy. All participants gave signed informed consent in Imam-Ali educational Hospital of Zahedan University of Medical Sciences from March 2010 to October 2011. We selected all cases in the same sex to exclude the effect of sex on our results. The exclusion criteria were chronic pain diseases other than gallstone disease, use of opioids, tranquilizers, ste-

Copyright (c) 2014, Iranian Society of Regional Anesthesia and Pain Medicine (ISRAPM); Published by Kowsar. This is an open-access article distributed under the terms of the Creative Commons Attribution-NonCommercial 4.0 International License (http://creativecommons.org/licenses/by-nc/4.0/) which permits copy and redistribute the material just in noncommercial usages, provided the original work is properly cited. 
roids, NSAIDs and alcohol, patients with acute cholecystitis, neuromuscular diseases and bleeding disorders. A standard anesthetic was administered. Preoxygenation with $100 \% \mathrm{O}_{2}$ for 3 minutes, $2 \mu \mathrm{g} / \mathrm{kg}$ of fentanyl and 0.05 $\mathrm{mg} / \mathrm{kg}$ of midazolam was administrated after $5 \mathrm{ml} / \mathrm{kg}$ of crystalloids. For anesthesia induction, thiopenthal $5 \mathrm{mg} /$ $\mathrm{kg}$ followed by $0.15 \mathrm{mg} / \mathrm{kg}$ of cisatracurium was used to facilitate endotracheal intubation. Anesthesia was maintained with $60 \% \mathrm{~N}_{2} \mathrm{O}$ in oxygen and propofol $4-6 \mathrm{mg} / \mathrm{kg} / \mathrm{hr}$ (to keep cerebral state index at 40-60) and remifentanyl $0.05-0.5 \mu \mathrm{g} / \mathrm{kg} / \mathrm{min}$ (to maintain mean arterial blood pressure and pulse rates within $20 \%$ of the baseline).All patients received $1 \mu \mathrm{g} / \mathrm{kg}$ of fentanyl five minutes before the end of operation to reduce postoperative pain. Nasogastric tube was inserted for all patients after induction and was removed at the end of the surgery. A single surgeon performed all surgical procedures. The insufflated carbon dioxide was not warned and humidified. During laparoscopy, intra-abdominal pressure was maintained at $14 \mathrm{mmHg}$. Carbon dioxide was carefully evacuated at the end of the surgery by manual compression of the abdomen with open trocars. There are not any patients with irrigation abdomen with $0.9 \%$ saline during surgery. Patients were followed by a blind investigator for postoperative abdominal and shoulder pain using various methods, which include: visual analogue scale (VAS)- based on a $0-10$ scale with 0 meaning no pain and 10 meaning the most intense pain ever experienced-, postoperative analgesic requirements, presence of nausea and vomiting, time of unassisted ambulation, time of oral intake and time of return of bowel function in the recovery room and at 6,12 and 24 hours after operation (the time from end of anesthesia until presence of intestinal sound or first passage of flatus). We used intramuscular meperidine $0.5 \mathrm{mg} / \mathrm{kg}$ and $1 \mathrm{mg} / \mathrm{kg}$ as rescue analgesic for VAS $4-7$, and 8-10, respectively. Approximately 24 hours later, the patients were taken to the radiology department in a wheelchair; having sat up for at least the previous 30 minutes and a standing posteroanterior (PA) chest X-ray was taken. A consultant radiologist analyzed the X-rays. The length of the diaphragmatic arc and height of the gas bubble under each hemi-diaphragm was measured. The pneumoperitoneum was graded as absent, mild (1-5 $\mathrm{mm})$, moderate $(6-10 \mathrm{~mm})$ and severe $(>11 \mathrm{~mm})$. SPSS software for Windows, version 15 (SPSS Inc, Chicago, IL, USA) was used for statistical analyses. Arithmetic mean and standard deviation values for different variables were calculated and statistical analyses were performed for each group. We used Kruskal-Wallis test for comparison analysis. P value less than 0.05 was considered as significant.

\section{Results}

We studied 55 patients who underwent laparoscopic cholecystectomy. At the end, 17 (30.9\%) patients had no residual pneumoperitoneum after 24 hours, 23 (41.81\%) had mild residual pneumoperitoneum, 8 (14.54\%) had moderate and seven (12.72\%) had severe pneumoperitoneum. All patients were female. There were no statistically significant differences between groups in No significant difference was seen in all factors likely to increase postoperative pain including: bile spillage from punctured gallbladder, difficult dissection due to adhesions from previous surgery, bleeding, need to cholangiography, injury to bowels or other organs, and insertion of drain (Table 1). The abdominal and shoulder pain scores were significantly lower in the patients who had no or mild residual pneumoperitoneum than who had moderate to severe pneumoperitroneum in the recovery room and at 6,12 , and 24 hours postoperatively (Tables 2 and 3). The patients who had no or mild residual pneumoperitoneum required lower meperidine than patients with moderate to severe residual pneumoperitoneum (Table 4).

no significant difference was seen in frequency of nausea and vomiting, length of hospital stay, time of return of bowel function, time of unassisted ambulation, and time of oral intake (Table 5).

\begin{tabular}{lccccc}
\hline \multicolumn{2}{l}{ Table 1. Patients Data and Operation Characteristics ${ }^{\mathrm{a}}$} & & & \\
\hline Residual pneumoperitoneum & Trace & Mild & Moderate & Severe \\
\hline Age, $\mathbf{y}$ & $44.17 \pm 4.99$ & $45.04 \pm 4.79$ & $43.50 \pm 2.44$ & $44.00 \pm 2.45$ \\
Weight, $\mathbf{k g}$ & $62.88 \pm 4.64$ & $62.08 \pm 4.06$ & $60.87 \pm 2.03$ & $61.00 \pm 2.16$ \\
Height, $\mathbf{c m}$ & $158.0 \pm 5.04$ & $156.95 \pm 4.33$ & $156.25 \pm 2.12$ & $156.0 \pm 5.37$ \\
Duration of surgery, min & $100.0 \pm 18.11$ & $101.52 \pm 18.36$ & $103.12 \pm 11.31$ & $96.42 \pm 8.99$ & 0.509 \\
\hline
\end{tabular}

${ }^{\mathrm{a}}$ Data are presented as Mean $\pm \mathrm{SD}$.

\begin{tabular}{|c|c|c|c|c|c|}
\hline Residual pneumoperitoneum & Trace & Mild & Moderate & Severe & PValue \\
\hline In the recovery room, mg & $2.76 \pm 0.83$ & $3.60 \pm 1.03$ & $5.00 \pm 1.60$ & $5.42 \pm 1.61$ & 00 \\
\hline At 6 hours, mg & $2.47 \pm 0.94$ & $3.26 \pm 1.25$ & $4.62 \pm 1.40$ & $5.14 \pm 1.34$ & 00 \\
\hline At 12 hours, mg & $1.64 \pm 0.78$ & $2.47 \pm 0.99$ & $3.62 \pm 1.40$ & $4.14 \pm 1.34$ & 00 \\
\hline At 24 hours, mg & $0.88 \pm 0.69$ & $1.65 \pm 0.88$ & $2.75 \pm 1.28$ & $3.42 \pm 1.13$ & 00 \\
\hline
\end{tabular}

\footnotetext{
$\mathrm{a}$ Data are presented as Mean $\pm \mathrm{SD}$.
} 
Sabzi Sarvestani A et al.

\begin{tabular}{lccccc}
\hline \multicolumn{1}{l}{ Table 3. Visual Analogue Shoulder Pain Scores in Groups ${ }^{\mathrm{a}}$} & & & & \\
\hline Residual pneumoperitoneum & Trace & Mild & Moderate & Severe & PValue \\
\hline In the recovery room, $\mathbf{m g}$ & $2.41 \pm 0.79$ & $3.26 \pm 1.00$ & $4.62 \pm 1.40$ & $5.14 \pm 1034$ & 00 \\
At 6 hours, $\mathbf{m g}$ & $2.05 \pm 0.82$ & $2.95 \pm 1.02$ & $4.25 \pm 1.48$ & $4.85 \pm 1.57$ & 00 \\
At 12 hours, $\mathbf{m g}$ & $1.41 \pm 0.71$ & $2.08 \pm 0.84$ & $3.00 \pm 1.19$ & $3.85 \pm 1.06$ & 00 \\
At 24 hours, $\mathbf{m g}$ & $0.70 \pm 0.58$ & $1.21 \pm 0.73$ & $2.25 \pm 1.16$ & $3.42 \pm 0.78$ & 00 \\
\hline
\end{tabular}

${ }^{\mathrm{a}}$ Data are presented as Mean $\pm \mathrm{SD}$.

Table 4. Postoperative Meperidine Requirements in Groups a

\begin{tabular}{lccccc}
\hline Residual pneumoperitoneum & Trace & Mild & Moderate & Severe & Pvalue \\
\hline In the recovery room, mg & $5.41 \pm 12.05$ & $20.13 \pm 15.14$ & $26.75 \pm 20.23$ & $30.00 \pm 17.35$ & 0.008 \\
At 6 hours, $\mathbf{m g}$ & $3.70 \pm 10.47$ & $14.86 \pm 15.97$ & $22.75 \pm 14.05$ & $25.57 \pm 11.31$ & 0.009 \\
At 12 hours, $\mathbf{m g}$ & 00 & $5.30 \pm 11.86$ & $15.25 \pm 16.31$ & $21.14 \pm 14.49$ & 0.001 \\
At 24 hours, $\mathbf{m g}$ & 00 & 00 & $7.50 \pm 13.88$ & $16.85 \pm 15.81$ & 00 \\
Total & $9.11 \pm 21.37$ & $40.43 \pm 35.83$ & $72.25 \pm 54.77$ & $93.57 \pm 50.05$ & 00 \\
Doses & $0.29 \pm 0.68$ & $1.30 \pm 1.14$ & $2.25 \pm 1.58$ & $3.00 \pm 1.52$ & 00 \\
\hline
\end{tabular}

${ }^{\mathrm{a}}$ Data are presented as Mean $\pm \mathrm{SD}$.

Table 5. Recovery Variables Between Groups ${ }^{a}$

\begin{tabular}{lccccc}
\hline Residual pneumoperitoneum & Trace & Mild & Moderate & Severe & Pvalue \\
\hline Time of oralin take, $\mathbf{h}$ & $13.41 \pm 5.44$ & $12.60 \pm 4.07$ & $12.12 \pm 5.54$ & $13.71 \pm 4.88$ & 0.803 \\
$\begin{array}{l}\text { Time of unassisted ambula- } \\
\text { tion, } \mathbf{h}\end{array}$ & $15.17 \pm 4.54$ & $13.82 \pm 4.57$ & $13.75 \pm 5.00$ & $15.42 \pm 5.34$ & 0.589 \\
Time of bowel function, $\mathbf{h}$ & $21.23 \pm 2.86$ & $20.00 \pm 4.97$ & $20.50 \pm 3.02$ & $22.71 \pm 3.09$ & 0.581 \\
Time of hospital stay, $\mathbf{h}$ & $24.76 \pm 3.66$ & $24.17 \pm 3.77$ & $23.87 \pm 3.13$ & $25.85 \pm 3.28$ & 0.368 \\
\hline
\end{tabular}

$\mathrm{a}$ Data are presented as Mean \pm SD.

\section{Discussion}

Provision of adequate postoperative pain relief is of considerable importance following day-case laparoscopic cholecystectomy (6). It is suggested that postlaparoscopic cholecystectomy pain have multiple factors and methods for short term analgesia cannot improve postoperative functions or hospitalization stay (7). Several factors including patient demographic factors, underlying disease, surgical factors, volume of residual gas, type of gas used for pneumoperitoneum, and the pressure created by the pneumoperitoneum affect post laparoscopic cholecystectomy pain (7-12).

Some authors have reported relation between residual pneumoperitoneum and post laparoscopic cholecystectomy pain and tried to reduce pain after gas removal by drainage in the postoperative period in both gynecologic (13) and general (14) surgical settings; others have not confirmed these findings (15). To the best of the authors' knowledge, there is not any study to show relationship between volume of residual pneumoperitoneum and postlaparoscopic pain intensity that measured by a standard pain score. Only one study by Jackson et al. (16) showed that residual pneumoperitoneum volume is related to postlaparoscopic pain in gynecologic operations and they suggested that more residual pneumopritoneum is related to more degree of pain by more diaphragm irritation. Other studies showed that active aspiration of the pneumoperitoneum and intra peritoneal drain after laparoscopic surgery could reduce pain significantly $(7,17)$.

In our study, patients who had no or minor residual pneumoperitoneum volume had lower pain scores compared with whom with moderate to severe without any differences in demographic data and operation characteristics. This difference can explain by more irritation of diaphragm and peritoneum in patients with more residual pneumoperitoneum volume that produce more pain for patients. Millitz et al. in 1994 (18) showed no pneumoperitoneum in $30(60 \%)$ of patients in the day after operation. Fourteen patients (28\%) had less than 5 $\mathrm{mm}$ pneumoperitoneum and $6(12 \%)$ had $6-10 \mathrm{~mm}$ pneumoperitoneum, while they expelled carbon dioxide at the end of surgery through the ports by opening the cannulas and removing the instruments. In our study the patients have more pneumoperitoneum at the day after surgery in spite of active aspiration. Seventeen pa- 
tients (30.9\%) had no pneumoperitoneum, 23 (41.81\%) had mild, eight (14.54\%) had moderate and seven (12.72\%) had severepneumoperitoneum. This shows that our surgeons paid less attention to aspirate carbon dioxide at the end of surgery; therefore, the necessity of more careful active aspiration by our surgeons at the end of surgery should be noticed.

In our study, patients who had no or minor residual pneumoperitoneum volume had lower analgesic requirement compared with whom with moderate to severe form. Fredman et al. (5) showed patients in whom the pneumoperitoneum gas was actively aspirated at the end of surgery during the first postoperative hour (AA group) made significantly fewer demands for patientcontrolled analgesia (PCA) morphine and received less intravenous morphine from their PCA devices compared with those patients in whom no attempt was made to remove residual pneumoperitoneum. Perhaps the deep abdominal and referred shoulder pain experienced by patients after laparoscopic cholecystectomy is aggravated by the continual stretching and irritation of the peritoneum by free residual carbon dioxide (CO2).

The incidence of postoperative nausea and vomiting af ter laparoscopic procedures ranges from 10 to 60\% (19). The pathogenesis of postoperative nausea and vomiting is multifactorial, depending on anesthesia, surgery, gender and perioperative administration of opioids (20). Frequency of nausea and vomiting in our study (29-42\%), despite differences in residual pneumoperitoneum and postoperative pain, did not have any significant difference $(P=0.51)$. It shows that other factors more than pain and residual pneumoperitoneum have effects on frequency of nausea and vomiting.

Das et al. (21) compared postoperative pain and recovery variables between active gas reduction group (Group $1, \mathrm{n}=105$ ) and the control group (Group 2, $\mathrm{n}=95$ ). They showed no difference in recovery variables despite differences of postoperative pain between two groups. There was not any difference in recovery variables including time of unassisted ambulation, time of oral intake and time of return of bowel function between groups despite differences in other variables like postoperative pain and analgesic requirements. Therefore, factors affecting pain and analgesic requirements has no effect on recovery variables. Our conclusions could be more reliable if we could include more samples (number of patients in moderate and severe group was small).

Our study showed that volume of residual pneumoperitoneumis related to postlaparoscopic cholecystectomy pain intensity. Patients with no or mild residual pneumoperitoneum have lower pain scores and analgesic usage and our surgeons should pay more attention in active aspiration of carbon dioxide at the end of laparoscopic operations.

\section{Acknowledgements}

We would like to thank Imam Ali hospital general oper- ating room and surgical ward personnel for their contribution to this study.

\section{Authors' Contributions}

Planning, data collection, analysis and article writing was done by Dr. Amene Sabzi Sarvestani and Dr. Mehdi Zamirisupervise all processes.

\section{References}

1. Greaves N, Nicholson J. Single incision laparoscopic surgery in general surgery: a review. Ann R Coll Surg Engl. 2011;93(6):437-40.

2. Milas M, Deveđija S, Trkulja V. Single incision versus standard multiport laparoscopic cholecystectomy: Up-dated systematic review and meta-analysis of randomized trials. The Surg J. 2014.

3. Tang B, Hanna GB, Joice P, Cuschieri A. Identification and categorization of technical errors by Observational Clinical Human Reliability Assessment (OCHRA) during laparoscopic cholecystectomy. Arch Surg. 2004;139(11):1215-20.

4. Ingelmo PM, Bucciero M, Somaini M, Sahillioglu E, Garbagnati $\mathrm{A}$, Charton A, et al. Intraperitoneal nebulization of ropivacaine for pain control after laparoscopic cholecystectomy: a double-blind, randomized, placebo-controlled trial. Br J Anaesth. 2013;110(5):800-6.

5. Fredman B, Jedeikin R, Olsfanger D, Flor P, Gruzman A. Residual pneumoperitoneum: a cause of postoperative pain after laparoscopic cholecystectomy. Anesth Analg. 1994;79(1):152-4.

6. Boddy AP, Mehta S, Rhodes M. The effect of intraperitoneal local anesthesia in laparoscopic cholecystectomy: a systematic review and meta-analysis. Anesth Analg. 2006;103(3):682-8.

7. Wills VL, Hunt DR. Pain after laparoscopic cholecystectomy. Br J Surg. 2000;87(3):273-84.

8. Koc M, Ertan T, Tez M, Kocpinar MA, Kilic M, Gocmen E, et al Randomized, prospective comparison of postoperative pain in low- versus high-pressure pneumoperitoneum. ANZ J Surg. 2005;75(8):693-6.

9. Ekici Y, Bozbas H, Karakayali F, Salman E, Moray G, Karakayali H, et al. Effect of different intra-abdominal pressure levels on QT dispersion in patients undergoing laparoscopic cholecystectomy. Surg Endosc. 2009;23(11):2543-9.

10. Bisgaard T, Kehlet H, Rosenberg J. Pain and convalescence after laparoscopic cholecystectomy. EurJ Surg. 2001;167(2):84-96.

11. Sandhu T, Yamada S, Ariyakachon V, Chakrabandhu T, Chongruksut W, Ko-iam W. Low-pressure pneumoperitoneum versus standard pneumoperitoneum in laparoscopic cholecystectomy, a prospective randomized clinical trial. Surg Endosc 2009;23(5):1044-7.

12. O'Boyle CJ, deBeaux AC, Watson DI, Ackroyd R, Lafullarde T, Leong JY, et al. Helium vs carbon dioxide gas insufflation with or without saline lavage during laparoscopy. Surg Endosc. 2002;16(4):620-5.

13. Swift G, Healey M, Varol N, Maher P, Hill D. A prospective ran domised double-blind placebo controlled trial to assess whether gas drains reduce shoulder pain following gynaecological laparoscopy. Aust N Z J Obstet Gynaecol. 2002;42(3):267-70.

14. Suginami R, Taniguchi F, Suginami H. Prevention of postlaparoscopic shoulder pain by forced evacuation of residual CO(2).JSLS. 2009;13(1):56-9.

15. Thomson AJ, Abbott JA, Lenart M, Willison F, Vancaillie TG, Bennett MJ. Assessment of a method to expel intraperitoneal gas after gynecologic laparoscopy. J Minim Invasive Gynecol. 2005;12(2):125-9.

16. Jackson SA, Laurence AS, Hill JC. Does post-laparoscopy pain relate to residual carbon dioxide? Anaesthesia. 1996;51(5):485-7.

17. Abbott J, Hawe J, Srivastava P, Hunter D, Garry R. Intraperitoneal gas drain to reduce pain after laparoscopy: randomized masked trial. Obstet Gynecol. 2001;98(1):97-100.

18. Millitz K, Moote DJ, Sparrow RK, Girotti MJ, Holliday RL, McLarty TD. Pneumoperitoneum after laparoscopic cholecystectomy: fre- 


\section{Sabzi Sarvestani A et al.}

quency and duration as seen on upright chest radiographs. AJR Am J Roentgenol. 1994;163(4):837-9.

19. Wilson EB, Bass CS, Abrameit W, Roberson R, Smith RW. Metoclopramide versus ondansetron in prophylaxis of nausea and vomiting for laparoscopic cholecystectomy. Am J Surg. 2001;181(2):138-41.

20. Neudecker J, Sauerland S, Neugebauer E, Bergamaschi R, Bonjer
HJ, Cuschieri A, et al. The European Association for Endoscopic Surgery clinical practice guideline on the pneumoperitoneum for laparoscopic surgery. Surg Endosc. 2002;16(7):1121-43.

21. Das K, Karateke F, Menekse E, Ozdogan M, Aziret M, Erdem H, et al. Minimizing shoulder pain following laparoscopic cholecystectomy: a prospective, randomized, controlled trial. J Laparoendosc Adv Surg Tech A. 2013;23(3):179-82. 